\title{
Intercostal muscle flap to reinforce the bronchial stump after video-assisted thoracic surgery pneumonectomy
}

\author{
Davide Tosi, Shehab Mohamed, Sara Pieropan, Cristina Diotti, Mario Nosotti \\ Thoracic Surgery and Lung Transplant Unit, Fondazione IRCCS Ca' Granda Ospedale Maggiore Policlinico, Milan, Italy \\ Correspondence to: Shehab Mohamed, MD, IRCCS. Thoracic Surgery and Lung Transplant Unit, Fondazione Cà Granda Ospedale Maggiore \\ Policlinico, Milan, Italy. Email: shehabmohamedmd@gmail.com.
}

\begin{abstract}
In open surgery, the buttressing of bronchial stump is a common procedure, in order to prevent the occurrence of bronchopleural fistula after anatomic resections in high-risk patients (i.e., chemotherapy, inflammatory disease, diabetes mellitus). Several techniques have been proposed for the prophylactic coverage of the bronchial stump, most of them using parietal pleura, pericardial fat pad, or intercostal muscle flap (IMF). In our Institution, we routinely cover the bronchial stump with an IMF, usually prepared before ribs spreading, for maintaining an adequate blood flow. IMF in video-assisted thoracic surgery (VATS) surgery is rarely utilized, there are only few descriptions in Literature. We describe a VATS procedure of protecting the bronchial stump with an IMF, harvested with an harmonic scalpel from the utility incision. We evaluated a patient for VATS pneumonectomy after induction chemotherapy. The patient was a 54-yearold woman, with an adenocarcinoma of the right lung, previously treated with chemotherapy for a huge hilar nodal involvement. The patient had a three-ports technique approach. In this case, the IMF was harvested with an harmonic scalpel from the under surface of the fifth rib, paying attention to not injure the vascular structures. The flap was transacted and sutured to the bronchial stump. The time required for harvesting the flap was very short, almost 5 minutes. This procedure helped to avoid negative consequences of pneumonectomy, without providing technical difficulties. In conclusion, we believe that IMF is a valid choice, increasing the vascularity of the bronchial stump; the procedure is easy to perform, even in VATS.
\end{abstract}

Keywords: Video-assisted thoracic surgery (VATS); pneumonectomy; bronchopleural fistula (BPF); intercostal muscle flap (IMF); bronchial stump

Received: 25 July 2019; Accepted: 03 September 2019; Published: 04 October 2019.

doi: $10.21037 /$ ccts.2019.09.01

View this article at: http://dx.doi.org/10.21037/ccts.2019.09.01

\section{Introduction}

Bronchopleural fistula (BPF) or dehiscence is a serious complication following anatomic pulmonary resections, with a reported incidence of $1-10 \%$ (1). It results in high comorbidity and mortality rates in additions to several other problems including infection, empyema, ARDS or air leak. The patients typically present with increasing subcutaneous emphysema, cough, temperature, respiratory distress and tachycardia.

Early bronchial stump failure is generally due to technical problems like staples misfiring, poor apposition of tissues or tension in the stump site. Late failure is usually caused by weak bronchial tissue or infection. Stapler closure, despite its various advantages, can cause more fistulization than manual closure, particularly in high risk patients (2).

Anyhow, we can find different risk factors related to the preoperative patient's state and clinical situation or to an intraoperative and postoperative management (3).

The major described preoperative risk factors are:

- Current smoking;

- Hyperglycemia and diabetes; 


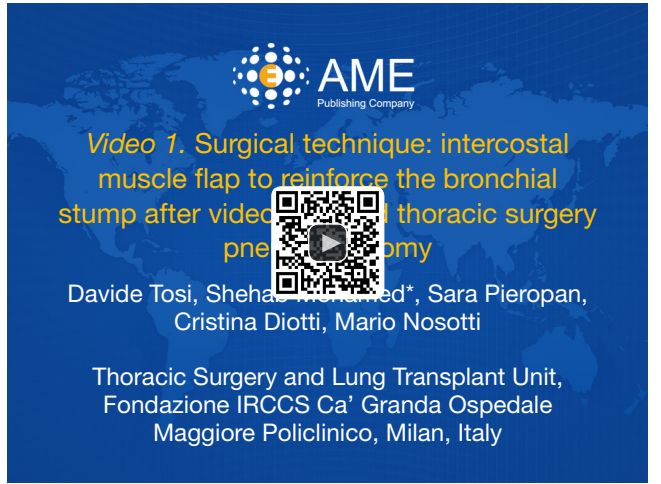

Figure 1 Surgical technique: intercostal muscle flap to reinforce the bronchial stump after video-assisted thoracic surgery pneumonectomy (4).

Available online: http://www.asvide.com/watch/32962

- Malnutrition and hypoalbuminemia;

- Previous steroid therapy;

- Copd and decreased pulmonary function;

- Neo-adjuvant chemotherapy or radiation;

- Antimetabolite and antiproliferative medications.

Intraoperative or postoperative risk factors are:

- Bronchial stump length;

- Right pneumonectomy;

- Prolonged mechanical ventilation;

- Loss of suture integrity;

- Postoperative empyema.

The most important therapy for bronchial stump fistula is prevention: recognizing and correcting risk factors and using a controlled ventilation decrease stump dehiscence. Often a prophylactic coverage of the bronchial stump is required, even during video-assisted thoracic surgery (VATS) procedures, so pleural and pericardial patches, ipsilateral pedicled latissimus dorsi flap and intercostal muscle flap (IMF) have been proposed.

In this video we show a case of a VATS procedure with bronchial stump coverage with an IMF, harvested with an harmonic scalpel from the utility incision (Figure 1).

\section{Patient and methods}

The patient was a 54-year-old woman, former smoker, admitted to our department with multiple lesions in the right lung and ilo-mediastinal lymphadenopathy. We diagnosed lung adenocarcinoma (TTF-1 positive, ALK-
KRAS-EGFR negative) with CT-guided FNAB. After four cycles of neoadjuvant chemotherapy with Gemcitabine and Cisplatin, a three portal VATS right pneumonectomy was planned. A $10.5 \mathrm{~mm}$ thoracoscope was inserted in the 8th intercostal space at the mid-axillary line. A $4 \mathrm{~cm}$ working port was placed in the anterior axillary line in the fourth intercostal space. A $1.5 \mathrm{~cm}$ assistant's port was placed in the 8th intercostal space at the subscapular lines. The bronchial closure was performed with endostapler (EndoGIA, Covidien); the stump was tested under sterile warm saline with ventilator pressure of $25 \mathrm{cmH}_{2} \mathrm{O}$. After that, the intercostal flap was dissected and harvested with an harmonic scalpel (Harmonic ACE - Ethicon) from the inferior margin of the fourth rib, with attention paid to avoid an injury to the vascular structures. The flap was then transected and sutured to the bronchial stump with an interrupted absorbable suture (PDS 4/0 Ethicon). The time required for harvesting the flap was very short, about 5-10 minutes. The postoperative course was without complications. We removed the chest tube on the fourth day. TNM staging was y p T1b N2.

\section{Discussion}

The use of intercostal muscle is commonly employed to protect and revascularize bronchial stumps or anastomoses after lung resections, particularly after pneumonectomy or sleeve lobectomy.

Sagawa et al. have reported a case of harvesting an IMF in a patient undergoing lobectomy through a VATS approach (5). Reinforcement of bronchial stump could be therefore performed even during minimally invasive surgery for higher-risk patients, as well described by Serna-Gallegos et al. (6).

Bronchopleural fistula can be safely prevented after pulmonary resection even in high risk patients undergoing neoadjuvant chemoradiation therapy, as described by Cerfolio et al. (7). However, in patients undergoing pneumonectomy, the right bronchial stump is at greater risk than any other part of the bronchial tree; in this paper, 2 out of 11 pneumonectomies developed BPF even after ICM flap buttressing. This study recommends using the omental or the serratus as a prophylactic buttress for the highly irradiated right main stem bronchus after right pneumonectomy.

Cerfolio et al. also demonstrated, through a prospective 
randomized trial on 114 lobectomy patients, that harvesting IMF before ribs spreading decreases the thoracotomyrelated pain and leads to a lower decrease in spirometric values (8). The same group later published the results of a prospective randomized trial on harvesting and then leaving the ICM flap intact instead of cutting it before rib spreading, resulting in further decreased thoracotomy postoperative pain (9).

The blood supply is dependent on the absence of injury to the artery and vein, or other problems after transposition into the chest. To avoid ischemic injury, it is crucial that the muscle flap should be harvested without an excessive pedicle skeletonization and with an appropriate length.

A study on the quality of the pedicle IMF using indocyanine green fluorescence has been described by Llewellyn-Bennett $e t$ al. this study showed that ICM flap thickness and length had an important impact on the length of the ischemic segment (10).

Since thoracotomy-related pain significantly impacts patients in the postoperative period, we emphasize the importance of VATS approach, particularly in high-risk patients. The IMF is not injured during this procedure, because ribs are not spread, thus, improving the quality of the pedicle; the surgeon can harvest the IMF before the pulmonary resection or even after, allowing to decide during the operation if the bronchial buttressing would be necessary. If a pneumonectomy or a sleeve resection is planned, the IMF can be easily prepared during utility thoracotomy.

In conclusion, we consider intercostal flap as a valuable choice, easy to perform in all bronchial stumps, even during VATS procedures; it can be harvested before or after the pulmonary resection, and represents a valid choice to reduce complications, especially in high-risk patients.

\section{Acknowledgments}

Funding: None.

\section{Footnote}

Conflicts of Interest: All authors have completed the ICMJE uniform disclosure form (available at http://dx.doi. org/10.21037/ccts.2019.09.01). The authors have no conflicts of interest to declare.
Ethical Statement: The authors are accountable for all aspects of the work in ensuring that questions related to the accuracy or integrity of any part of the work are appropriately investigated and resolved. I confirm that the written informed consent was obtained from the patient.

Open Access Statement: This is an Open Access article distributed in accordance with the Creative Commons Attribution-NonCommercial-NoDerivs 4.0 International License (CC BY-NC-ND 4.0), which permits the noncommercial replication and distribution of the article with the strict proviso that no changes or edits are made and the original work is properly cited (including links to both the formal publication through the relevant DOI and the license). See: https://creativecommons.org/licenses/by-nc-nd/4.0/.

\section{References}

1. Algar FJ, Alvarez A, Aranda JL, et al. Prediction of early bronchopleural fistula after pneumonectomy: a multivariate analysis. Ann Thorac Surg 2001;72:1662-7.

2. Uçvet A, Gursoy S, Sirzai S, et al. Bronchial closure methods and risks for bronchopleural fistula in pulmonary resections: how a surgeon may choose the optimum method? Interact Cardiovasc Thorac Surg 2011;12:558-62.

3. Liberman M, Cassivi SD. Bronchial stump dehiscence: update on prevention and management. Semin Thorac Cardiovasc Surg 2007;19:366-73.

4. Tosi D, Mohamed S, Pieropan S, et al. Surgical technique: intercostal muscle flap to reinforce the bronchial stump after video-assisted thoracic surgery pneumonectomy. Asvide 2019;6:277. Available online: http://www.asvide. com/watch/32962

5. Sagawa M, Sugita M, Takeda Y, Toga H, Sakuma T. Videoassisted bronchial stump reinforcement with an intercostal muscle flap. Ann Thorac Surg 2004;78:2165-6.

6. Serna-Gallegos DR, McKenna RJ Jr. Video-Assisted Intercostal Muscle Flaps for Bronchial Stump Coverage. Ann Thorac Surg 2017;103:e215-7.

7. Cerfolio RJ, Bryant AS, Jones VL, et al. Pulmonary resection after concurrent chemotherapy and high dose (60Gy) radiation for non-small cell lung cancer is safe and may provide increased survival. Eur J Cardiothorac Surg 2009;35:718-23; discussion 723.

8. Cerfolio RJ, Bryant AS, Patel B, et al. Intercostal muscle flap 
reduces the pain of thoracotomy: a prospective randomized trial. J Thorac Cardiovasc Surg 2005;130:987-93.

9. Cerfolio RJ, Bryant AS, Maniscalco LM. A nondivided intercostal muscle flap further reduces pain of thoracotomy: a prospective randomized trial. Ann Thorac
Surg 2008;85:1901-6; discussion 1906-7.

10. Llewellyn-Bennett R, Wotton R, West D. Prophylactic flap coverage and the incidence of bronchopleural fistulae after pneumonectomy. Interact Cardiovasc Thorac Surg 2013;16:681-5.

doi: $10.21037 /$ ccts.2019.09.01

Cite this article as: Tosi D, Mohamed S, Pieropan S, Diotti C, Nosotti M. Intercostal muscle flap to reinforce the bronchial stump after video-assisted thoracic surgery pneumonectomy. Curr Chall Thorac Surg 2019;1:14. 